\title{
Peran Orang Tua dalam Mengembangkan Perilaku Wirausaha Petani Muda Hortikultura di Daerah Istimewa Yogyakarta
}

\author{
Siti Nurlaela ${ }^{1 *}$, Sunarru Samsi Hariadi ${ }^{2}$, Alia Bihrajihat Raya ${ }^{3}$ \\ ${ }^{1}$ Jurusan Penyuluhan Pertanian Berkelanjutan, Politeknik Pembangunan Pertanian \\ Yogyakarta-Magelang \\ ${ }^{2}$ Program Studi Penyuluhan dan Komunikasi Pembangunan, Sekolah Pascasarjana, Universitas \\ Gadjah Mada (UGM), Yogyakarta \\ ${ }^{3}$ Penyuluhan dan Komunikasi Pertanian, Departemen Sosial-Ekonomi Pertanian, Fakultas \\ Pertanian, Universitas Gadjah Mada (UGM), Yogyakarta \\ *Corresponding author: nurlaela77yk@gmail.com
}

\begin{abstract}
Abstrak
Minat pemuda menjadi petani sangat rendah. Diperlukan berbagai upaya untuk mengatasi permasalahan ini. Orang tua memiliki pengaruh yang besar dalam menunjang kewirausahaan pertanian anaknya. Penelitian ini bertujuan untuk menganalisis pengaruh peran orang tua dalam mengembangkan perilaku wirausaha petani muda hortikultura. Penelitian ini dirancang sebagai penelitian survei. Dengan teknik simple random sampling, didapatkan responden sebanyak 300 petani muda. Hasil penelitian menunjukkan bahwa lama wirausaha, dan peran orang tua memengaruhi perilaku wirausaha hortikultura. Lama usaha berpengaruh negatif, sementara peran orang tua berpengaruh positif. Pengaruh peran orang tua dan lama usaha $(p \leq 0,05)$ secara bersamasama terhadap perilaku wirausaha hortikultura (R Square) sebesar 12,6\%. Pemerintah diharapkan terus mendorong program regenerasi petani muda melalui sinergi peran orang tua dan anak, terutama pada petani yang baru memulai usaha dengan memberikan pelatihan dan memfasilitasi permodalan, menfasilitasi penggunaan media baru yang mendukung pengembangan wirausaha petani muda.
\end{abstract}

Kata kunci: Petani muda, Perilaku wirausaha, Hortikultura, Peran orang tua

\begin{abstract}
Youth interest in becoming farmers is deficient. Various efforts are needed to overcome this problem. Parents have a significant influence on supporting their children's agricultural entrepreneurship. This study aims to analyze the influence of parents' role in developing young horticultural farmers' entrepreneurial behavior. This study was designed as survey research. With a simple random sampling technique, it was found that 300 young farmers were respondents. The results showed that the length of entrepreneurship and the role of parents influenced horticultural entrepreneurial behavior. The length of business has a negative effect, while the role of parents has a positive effect. The effect of the role of parents and length of business $(p \leq 0.05)$ together on horticultural entrepreneurial behavior ( $R$ Square) is $12.6 \%$. The government is expected to continue to encourage the regeneration of young farmers through the synergy of parents and children's roles, especially for farmers who have just started a business by providing training and facilitating capital, facilitating the use of new media that support the entrepreneurial development of young farmers.
\end{abstract}

Keywords: Young farmers, Entrepreneurial behavior, Horticulture, The role of parents 
Prosiding Seminar Nasional Pembangunan dan Pendidikan Vokasi Pertanian Politeknik Pembangunan Pertanian Manokwari, 14 November 2020

e ISSN : 2774-1982

\section{PENDAHULUAN}

Pertanian menjadi sektor yang sangat penting dalam pembangunan di Indonesia, karena dapat memberikan kontribusi pada peningkatan pendapatan negara dan penyerapan tenaga kerja. Jumlah tenaga kerja yang terlibat di sektor pertanian sebesar 36,96 juta orang, namun selanjutnya mengalami penurunan pada tahun 2018 sebesar 29,2\%. Jumlah tenaga kerja yang besar tersebut, ternyata hanya mampu memberikan kontribusi PDB nasional pada triwulan I sebesar 9,96\% (Pusat Data dan Sistem Informasi Pertanian, 2018). Kondisi ini menunjukkan bahwa produktivitas tenaga kerja sektor pertanian masih rendah. Salah satu penyebabnya adalah faktor usia petani yang mayoritas telah berusia lanjut. Rendahnya jumlah pemuda yang terlibat di sektor pertanian ini ditunjukkan dengan persentase usia 35 tahun hanya $8,78 \%$ (BPS, 2018). Persentase yang sedikit ini dikarenakan beralihnya minat pemuda pada pekerjaan non pertanian.

Minat pemuda yang terus menurun dikarenakan semakin sempitnya lahan yang berdampak pada rendahnya pendapatan petani. Berdasarkan data BPS, mayoritas $(97,56 \%)$ petani di Daerah Istimewa Yogyakarta memiliki lahan di bawah satu hektar (2018). Masalah rendahnya pendapat ini diharapkan dapat diatasi dengan meningkatkan kemampuan wirausaha. Kemampuan wirausaha diperkirakan dapat meningkatkan hasil dan nilai tambah dari keterbatasan permodalan dan lahan yang dimiliki. Apalagi bagi petani kecil yang tidak memungkinkan untuk menambah luasan tanahnya (Wanyonyi \& Bwisa, 2015). Perilaku wirausaha bagi petani mutlak diperlukan karena salah satu alternatif untuk meningkatkan kesejahteraan keluarga petani adalah melakukan efisiensi dan efektivitas dalam berwirausaha (Mcelwee, 2006; Lans et al., 2017).

Hal ini seiring dengan program pemerintah melalui Dinas Pertanian Daerah Istimewa Yogyakarta yang terus berupaya meningkatkan kapasitas petani dan pengembangan kawasan sentra hortikultura. Berdasarkan LKIP Dinas Pertanian DIY (2017) terdapat tiga komoditas unggulan yang diharapkan dapat menopang keberlangsungan kebutuhan hortikuktura di DIY, yakni: cabai, bawang merah dan salak. Komoditas ini diminati petani karena relatif menguntungkan dibandingkan dengan komoditas lainnya. Di samping itu, hortukultura (terutama buah dan sayur) memiliki nilai ekonomi tinggi, kebutuhan lahan sempit, dapat ditanam di lahan kering, dan peluang pasar yang sangat luas. Hal ini dapat dilihat dari data impor hortikultura tahun 2018 sebesar 2,06 juta USD atau sekitar Rp 28 trilyun (Santosa, 2019). Namun, peluang ini belum membuat pemuda tertarik menekuni usahatani hortikultura karena harga panen komoditas hortikultura yang sangat fluktuatif. Masalah terbesar petani hortikutura adalah jika terjadi 
Prosiding Seminar Nasional Pembangunan dan Pendidikan Vokasi Pertanian Politeknik Pembangunan Pertanian Manokwari, 14 November 2020

e ISSN : 2774-1982

panen raya, biasanya harganya jauh di bahwa biaya produksi. Petani cabai sering mengalami kerugian karena fluktuasi harga yang tidak menentu ini (Novi, 2018). Pemerintah diharapkan dapat mendorong agar pemuda terutama di sentra hortikultura dapat memafaatkan peluang ini dan sekaligus dapat terus melanjutkan usahatani orang tuanya.

Wiyono (2015) menyebutkan bahwa pada petani hortikultura, orang tua merupakan pemberi pengaruh yang paling besar $(70 \%)$ bagi anaknya menjadi wirausaha. Besarnya dorongan orang tua karena petani hortikultura memiliki nilai ekonomi yang lebih baik. Pengaruh orang tua menjadi sarana yang efektif dalam menentukan pilihan berwirausaha anaknya. Selain itu, mereka yang dibesarkan di lingkungan pertanian telah belajar tanggung jawab, strategi kerja, kemandirian, inisiatif, penyelesaian masalah, dan lingkungan serta koneksi dari orang tuanya. Orangtua memiliki peran yang penting dalam mengarahkan profesi dan pekerjaan anaknya di masa depan, terutama dalam pertanian (Pant, 2015). Ditinjau dari perspektif Psikologi Sosial, Kurt Lewin dalam penelitian Schneider menyatakan bahwa perilaku seseorang dipemgaruhi oleh faktor personal dan lingkungan. (Schneider et al., 2014), yang dirumuskan dalam persamaan $\mathrm{B}=\mathrm{f}(\mathrm{P}, \mathrm{E})$. Behavior atau perilaku merupakan fungsi dari Personal (P)/diri dan Environtmen/lingkungan. Peran orang tua dalam membetuk perilaku wirausaha anaknya sangat besar karena sejak kecil anak mengamati kegiatan orang tuanya. Selanjutnya Walgito (2011) menyatakan bahwa berperilaku adalah kebiasaan bertindak yang terdiri dari pola-pola perilaku yang dalam suatu kegiatan. Pembentukan tingkah laku secara garis besar dapat dilakukan dengan tiga hal: karena pemahaman (insight), pembiasaan, dan mengikuti/modelling (Walgito, 2011). Perilaku wirausaha dapat dilakukan oleh seseorang karena ketiganya, dan dalam hal ini orang tua dapat berperan penting dalam membentuk perilaku anak dalam berwirausaha. Noorani (2015) menyatakan bahwa orangtua dianggap sebagai role model dan motivator dalam berusahatani para pemuda karena keberhasilan mereka.

Berdasarkan pemaparan tersebut maka, penelitian ini bertujuan unutk menganalisis: perilaku wirausaha pada petani muda horikultura, peran orangtua dalam mengembangkan perilaku wirausaha pada anaknya, pengaruh peran orang tua terhadap perilaku wirausaha, pengaruh lama usaha terhadap perilaku usaha, dan pengaruh peran orang tua serta lama usaha secara bersama-sama terhadap perilaku usaha. Hasil penelitianini diharapkan dapat menjadi masukan dalam mengembangkan strategi regenerasi petani. 
Prosiding Seminar Nasional Pembangunan dan Pendidikan Vokasi Pertanian

Politeknik Pembangunan Pertanian Manokwari, 14 November 2020

e ISSN : 2774-1982

\section{METODE PENELITIAN}

Lokasi penelitian berada di daerah penghasil komoditas hortikultura di Daerah Istimewa Yogyakarta yang meliputi tiga kabupaten yaitu; Bantul, Kulon Progo dan Sleman. Penelitian dilaksanakan pada bulan Januari-Mei 2019. Kriteria responden yang memenuhi syarat dalam penelitian ini adalah: petani muda yang berwirausaha hortikultura dengan rentang usai 17 - 40 tahun dan tergabung dalam kelompok. Populasi berjumlah 604. Pengambilan sampel dilakukan dengan simple random sampling. Jumlah sampel yang diambil 300 orang. Pengumpulan data dilakukan dengan kuisioner tertutup. Variabel penelitian meliputi peran orang tua dan perilaku wirausaha. Variabel peran orang tua dan perilaku wirausaha diukur menggunakan skala penilaian 5 skor yang meliputi; (1) Tidak Pernah (TP), (2) Jarang (J), (3) Kadang-Kadang (K), (4) Sering (S), (5) Selalu (SL), sedangkan lama usaha diukur dalam tahun. Persentase dan mean digunakan untuk menganalisis karakteristik pribadi petani muda, peran orang tua, dan perilaku wirausaha. Pengaruh faktor determinan terhadap perilaku wirausaha dilakukan dengan analisis regresi linier berganda. Model statistiknya adalah sebagai berikut:

$$
\mathrm{Y}=\mathrm{k}+\mathrm{aX} 1+\mathrm{bX} 2
$$

Deskripsi:

Y: Perilaku Wirausaha

k: Konstan

X1: Peran OrangTua

X2: Lama Usaha 
Prosiding Seminar Nasional Pembangunan dan Pendidikan Vokasi Pertanian Politeknik Pembangunan Pertanian Manokwari, 14 November 2020

e ISSN : 2774-1982

\section{HASIL DAN PEMBAHASAN}

Tabel 1 menunjukkan bahwa mayoritas petani muda adalah laki-laki $(83,33 \%)$ dengan rata-rata usia 32,58 tahun, dan sebagian besar ada pada rentang 30-40 tahun.

Tabel 1. Karaktersitik Petani Muda Hortikultura

\begin{tabular}{|c|c|c|}
\hline Variabel & Persentase $(n=300)$ & Mean \\
\hline \multicolumn{3}{|l|}{ Jenis Kelamin } \\
\hline Laki-Laki & 83 & \\
\hline Perempuan & 17 & \\
\hline \multicolumn{3}{|l|}{ Pendidikan } \\
\hline SD & 1,33 & \\
\hline SMP & 13,33 & \\
\hline SMA & 74 & 12,07 \\
\hline Universitas & 11,33 & \\
\hline \multicolumn{3}{|l|}{ Usia } \\
\hline$<20$ & 6,67 & \\
\hline $21-25$ & 11,67 & \\
\hline $26-30$ & 17,67 & \\
\hline $31-35$ & 22,33 & 32,58 \\
\hline $36-40$ & 41,67 & \\
\hline Variabel & Persentase $(\mathrm{n}=\mathbf{3 0 0})$ & Mean \\
\hline \multicolumn{3}{|l|}{ Lama Usaha } \\
\hline $0-5$ & 39 & \\
\hline$>5-10$ & 38,33 & 8,25 \\
\hline$>10-15$ & 13,33 & \\
\hline$>15$ & 9,33 & \\
\hline
\end{tabular}

Sumber: Analisis Data Primer (2019)

Berdasarkan Tabel 1 petani muda laki-laki lebih banyak beraktivitas di bidang pertanian daripada perempuan. Kegiatan pertanian terutama produksi lebih banyak dilakukan oleh laki-laki. Jenjang pendidikan mayoritas responden adalah SMA/SMK (74\%). Tingkat pendidikan petani muda dapat menjadi modal SDM yang potensial, karena kemampuan kewirausahaan pertanian sangat mengandalkan SDM pemuda yang berkualitas. Rata-rata usia petani muda 32,58 tahun, dan lama usaha rata-rata 8,25 tahun.

Selanjutnya peran orang tua dalam mendukung kegiatan wirausaha anaknya terdapat pada Tabel 2. 
Prosiding Seminar Nasional Pembangunan dan Pendidikan Vokasi Pertanian

Politeknik Pembangunan Pertanian Manokwari, 14 November 2020

e ISSN : 2774-1982

Tabel 2. Peran Orang Tua dalam Mengembangkan Perilaku Wirausaha Petani Muda

\begin{tabular}{lc}
\multicolumn{1}{c}{ Aspek } & Mean \\
\hline Memberikan pengalaman usaha Memotivasi dalam & 2,98 \\
berwirausaha & 3,13 \\
Memberikan peluang usaha & 3,09 \\
\hline Mean & 3,06 \\
\hline
\end{tabular}

Sumber: Analisis Data Primer (2019)

Peranan orang tua dalam penelitian ini dimaknai sebagai peranan orang tua dalam memberikan pengalaman usaha, memotivasi dalam berwirausaha, dan memberikan peluang usaha kepada anaknya. Secara umum nilai peranan orang tua pada taraf kadangkadang $(3,06)$. Peranan orang tua yang kadang-kadang ini nampak pada aspek memotivasi anak dalam berwirausaha $(3,13)$ dan memberikan peluang usaha $(3,09)$. Sementara itu pada aspek memberikan pengalaman usaha jarang dilakukan $(2,98)$. Hal ini terkait dengan kemandirian petani muda yang telah berusahatani dan berumah tangga sendiri. Dalam hal memberikan pengalaman usaha, orang tua melakukannya secara tidak langsung melalui aktivitas membantu bertani saat mereka belum hidup mandiri, juga dapat dikaitkan dengan usia rata-rata petani muda yaitu 32,58 tahun. Petani muda sudah tergolong individu yang mandiri dalam berusaha dan telah memiliki keluarga sendiri. Hal ini ditunjukkan dengan persentase petani muda yang telah menikah (76\%). Perannya sebagai kepala keluarga telah mendorong pemuda untuk mandiri, baik dalam aspek ekonomi maupun sosial. Santrock (2012) menyatakan bahwa peran pemuda dalam usia dewasa awal ditandai dengan memasuki dunia kerja. Pada tahap ini seseorang sudah mulai berpikir realistis karena pekerjaan dan tanggungjawabnya dalam keluarga.

Di lapangan dapat ditemukan bahwa petani muda telah mandiri dalam berusahatani mulai dari awal penyiapan modal, penyiapan lahan, budidaya sampai pemasaran. Pada petani cabai, upaya orang tua dalam memandirikan anak telah dilakukan sejak mereka masih sekolah. Upaya sejak dini ini menjadi temuan menarik yang perlu diperkuat oleh peran pemerintah dengan menfasilitasi petani muda karena cukup efektif menarik minat bertani, khususnya petani cabai. Pada petani salak dan petani bawang merah hal ini kurang nampak. Pada kedua komoditas ini, orang tua hanya sebatas meminta anak membantu usahatani orang tuanya saja, dan membiarkan anak memilih pekerjaan di luar pertanian. Orang tua yang kurang mendukung minat anak pada pertanian dapat mempengaruhi pilihan bertaninya.

Selanjutnya terkait dengan perilaku wirausha petani muda hortikultura terdapat pada Tabel 3 . 
Prosiding Seminar Nasional Pembangunan dan Pendidikan Vokasi Pertanian

Politeknik Pembangunan Pertanian Manokwari, 14 November 2020

e ISSN : 2774-1982

Tabel 3. Perilaku Wirausaha Petani Muda Hortikultura

\begin{tabular}{lr}
\hline Aspek & Mean \\
\hline Identifikasi Peluang Usaha & 3,48 \\
Memanfaatkan Peluang Usaha & 3,05 \\
Mengembangkan Usaha & 3,02 \\
Memanfaatkan Media Baru untuk Usaha & 3,02 \\
\hline Mean & 3,14 \\
\hline
\end{tabular}

Sumber: Analisis Data Primer (2019)

Berdasarkan Tabel 3 mean perilaku wirausaha secara umum pada level kadangkadang $(3,14)$. Hasil ini sesuai dengan penelitian (Mukti et al., 2018) yang menyatakan sebagian besar petani belum berorientasi pada pengembangan usaha. Perilaku mengidentifikasi peluang usaha $(3,48)$ kadang-kadang ditunjukkan dengan perilaku mencari informasi peluang usaha, menganalisis kebutuhan pasar dan menganalisis kelayakan usaha. Perilaku mengidentifikasi peluang dilakukan petani dengan menanam tanaman yang memiliki nilai ekonomis relatif tinggi. Hortikultura dalam hal ini cabai, bawang merah dan salak memiliki peluang pengembangan usaha yang menjanjikan. Sedangkan perilaku memanfaatkan peluang usaha $(3,05)$ kadang-kadang dilakukan dengan memanfaatkan potensi yang dimiliki, membuat produk yang baru/berbeda, memasarkan produk sesuai permintaan, memanfaatkan jejaring.

Perilaku mengembangkan usaha pada $(3,02)$ kadang-kadang dilakukan dengan meningkatkan kualitas dan kuantitas dan meningkatkan jejaring. Petani cabai telah melakukan inovasi dengan pasar lelang, petani salak dengan pengembangan agrowisata, sementara itu petani bawang merah belum melakukan pengembangan secara kelompok. Petani bawang merah baru mengembangkan penjualan secara personal pada wisatawan di pantai sekitar lokasi pertanian. Pengembangan pasar lelang cabai ini telah dilakukan petani berbasis kelompok dan dapat meningkatkan bargaining harga sebagainana penelitian Raya (2014).

Perilaku pemanfaatan media baru untuk usaha $(3,02)$ kadang-kadang ditunjukkan dengan melakukan akses informasi, interaksi dan transaksi. Petani salak memanfaatkan media baru untuk menunjang pengembangan agrowisata. Kelompok petani muda menggabungkan potensi pertanian dengan wisata alam. Mereka melakukan promosi menggunakan website dan media sosial lainnya (instagram, facebook, whattsapp). Media baru dapat membantu petani muda dalam memperpendek mata rantai pemasaran, sehingga harga komoditas bisa lebih baik (FAO, 2014), (Dhaka, 2010), (John et al., 2014). 
Prosiding Seminar Nasional Pembangunan dan Pendidikan Vokasi Pertanian Politeknik Pembangunan Pertanian Manokwari, 14 November 2020

e ISSN : 2774-1982

Tabel 4. Pengaruh Determinan Faktor terhadap Perilaku Wirausaha Petani Muda Hortikultura

\begin{tabular}{lrrrr}
\hline \multicolumn{1}{c}{ Variabel } & Koefisien Regresi & T hitung & \multicolumn{1}{c}{ Sign } & \multicolumn{1}{c}{ Ket } \\
\hline Lama Usaha (X1) & $-0,199$ & $-2,668$ & 0,000 & $* *$ \\
Peran Orang Tua (X2) & 0,281 & 5,168 & 0,000 & $* *$ \\
Konstanta & & 16,046 & 0,000 & $* *$ \\
\hline R Square & 0,126 & & & \\
Adjusted R Square & 0,120 & & & \\
F Hitung & 21,460 & & & \\
\hline
\end{tabular}

Sumber: Analisis Data Primer (2019)

Keterangan: *Signifikan pada taraf 5\%,** Signifikan pada taraf $1 \%$

Berdasarkan Tabel 4 pengaruh lama usaha dan peran orang tua terhadap perilkau wirausaha signifikan karena nilai $\mathrm{F}$ hitung $(21,460)>$ daripada $\mathrm{F}$ tabel $(3,02)$ pada taraf signifikansi $\mathrm{p} \leq 0,05$. Selanjutnya, persamaan regresi dari pengaruh lama usaha dan peran orang tua adalah: $\mathrm{Y}=\mathrm{k}+(-0,199) \mathrm{X} 1+0,281 \mathrm{X} 2$. Perilaku wirausaha dipengaruhi oleh lama usaha (X1) dan peran orang tua (X2). Pengalaman usaha berpengaruh negatif signifikan terhadap perilaku wirausaha, artinya semakin lama petani berwirausaha, maka tingkat perilaku wirausaha justru semakin rendah. Fenomena di lapangan menunjukkan bahwa petani yang lebih lama berwirausaha telah memiliki pengalaman dalam budidaya maupun jejaring yang sudah berkembang, dan berjalan stabil. Penelitian dengan hasil yang sama juga dinyatakan oleh Dhaka (2010) dan Khabir (2015) yang menyatakan bahwa petani yang sudah lama berpengalaman tidak tertarik untuk menambah keterampilan dalam memanfaatkan media baru.

Peran orag tua berpengaruh positif signifikan terhadap peningkatan perilaku wirausaha (Tabel 4). Artinya, semakin besar pengaruh peran orang tua, maka perilaku wirausaha akan semakin meningkat. Data penelitian ini menunjukkan bahwa sebanyak $89,67 \%$ pekerjaan orangtua petani muda adalah petani. Pewarisan yang secara turun temurun pada lahan orangtua menjadi alasan petani muda memilih pekerjaan ini. Orang tua berperan penting dalam mengarahkan pilihan profesi atau pekerjaan anaknya di masa depan (Hoffmann et al., 2015). Pada petani salak, orang tua yang telah berusia lanjut, akan menyerahkan pengelolaan kebunnya pada anak-anaknya. Demikian juga pada petani cabai dan bawang merah. Upaya orang tua akan berpengaruh dalam meningkatkan kemampuan wirausaha anaknya (Kutwa et al., 2016). Petani yang mendapatkan fasilitasi dan motivasi orang tuanya akan lebih berkembang daripada petani muda yang tidak diarahkan oleh orang tuanya. 
Prosiding Seminar Nasional Pembangunan dan Pendidikan Vokasi Pertanian

Politeknik Pembangunan Pertanian Manokwari, 14 November 2020

e ISSN : 2774-1982

\section{KESIMPULAN DAN SARAN}

Hasil penelitian ini kebaruannya adalah: bahwa orang tua dapat memberikan pengaruh yang besar pada usaha anaknya. Di tengah keengganan orang tua mengarahkan anaknya menjadi petani, maka petani hortikultura masih memiliki harapan agar anaknya meneruskan dan mengembangkan usahanya. Hal ini menunjukkan bahwa pada petani hortikultura telah terjadi proses pewarisan nilai yang dilakukan orang tua pada anaknya. Selanjutnya, pada petani muda yang baru memulai usaha, pengaruh orang tua lebih besar daripada petani yang telah lama berwirausaha. Hal ini dikarenakan petani yang lama berwirausaha telah memiliki kemampuan dalam mengelola usahnaya tanpa bantuan dari orang tuanya. Dari hasil penelitian ini, pemerintah diharapkan terus mendorong dan menfasilitasi petani dan anaknya dalam mengembangkan usaha hortikultura dengan memberikan pelatihan pemanfaatkan media baru, penguatan modal dan perluasan jejaring informasi dalam mengelola wirausaha, khususnya pada petani muda yang baru memulai berwirausaha, sehingga melahirkan agripreneur muda yang sukses,

\section{DAFTAR PUSTAKA}

BPS. (2018). Hasil Survei Pertanian Antar Sensus (SUTAS) 2018.

Dhaka, B. and C. K. (2010). Farmers' experience with ICTs Farmers' experience with ICTs on transfer of technology in changing Agri-rural Environment. Indian Research Journal of Extension Education. 10 (3), 114-118.

Dinas Pertanian DIY. (2017). Laporan Kinerja Instansi Pemerintah Dinas Pertanian DIY Tahun 2017.

FAO. (2014). Youth and Agriculture: Key Challenges and Concrete Solutions.

Hoffmann, A., Junge, M., \& Malchow-Møller, N. (2015). Running in The Family: Parental Role Models in Entrepreneurship. Small Business Economics, 44(1), 79-104. https://doi.org/10.1007/s11187-014-9586-0

John, G., Igwe, P. D., \& Abiye, S. R. P. D. (2014). ICT Entrepreneurship and Small Business Innovation: a Mechanism for Sustainability. European Journal of Business and Social Sciences, 3(6), 103-112.

Kutwa, A. A., Muhingi, W. N., \& Kokonya, D. (2016). Smallholder Rural Youth Farming in Kiambu County, Kenya. Journal Pf Culture, Society and Development, 25(November), 60-71.

Lans, T., Seuneke, P., Wageningen, A. H., \& Klerkx, L. (2017). Agricultural Entrepreneurship. January. https://doi.org/10.1007/978-1-4614-6616-1

Mcelwee, G. (2006). (PDF) Farmers As Entrepreneurs_ Developing Competitive Skills_ g.

Mukti, G. W., Rasmikayati, E., Kusumo, R., \& S Fatiman. (2018). Perilaku Kewirausahaan Petani Mangga dalam Sistem Agribisnis di Kabupaten Majalengka Jawa Barat. 
Prosiding Seminar Nasional Pembangunan dan Pendidikan Vokasi Pertanian

Politeknik Pembangunan Pertanian Manokwari, 14 November 2020

e ISSN : 2774-1982

Jurnal Pemikiran Masyarakat Ilmiah Berwawasan Agribisnis, 4(1), 40-56.

Novi. (2018). Faktor-Faktor yang Mempengaruhi Terjadinya Fluktuasi Harga Cabai Merah di Kabupaten Bireun. Jurnal S. Pertanian, 2(3), 264-271.

Pant, S. K. (2015). Role of The Family in Entrepreneurship Develoment in Nepali Society. IX(1), 37-47.

Pusat Data dan Sistem Informasi Pertanian. (2018). Statistik Ketenagakerjaan Sektor Pertanian Tahun 2017-2018 (Vol. 68, Issue 1).

Raya, A. B. (2014). Farmer Group Performance of Collective Chili Marketing on Sandy Land Area of Yogyakarta Province Indonesia. Asian Social Science, 10(10), 1-12. https://doi.org/10.5539/ass.v10n10p1

Santosa, D. A. (2019). Kinerja Sektor Pertanian dan Pangan Serta Prospek Tahun 2019.

Santrock. (2012). Life Span Development (Perkembangan Masa Hidup). Airlangga.

Schneider, K., Pierson, J., Bugental, J., Montuori, A., \& Purser, R. (2014). Humanistic Psychology in the Workplace. In The Handbook of Humanistic Psychology: Theory, Research, and Practice (pp. 723-734). SAGE Publications. https://doi.org/10.4135/9781483387864.n57

Walgito, B. (2011). Psikologi Suatu Pengantar. Andi Offset.

Wanyonyi, N. J., \& Bwisa, H. M. (2015). Factors Influencing Entrepreneurial Behavior Among Farmers: A Case Of Cabbage Farmers In Kiminini Ward. International Journal of Technologi Enhanncement and Emerging ERecearrch, 3(09).

Wiyono, S. (2015). Laporan Kajian Regenerasi Petani. In Koalisi Rakyat untu Kedaulatan Pangan dan Institut Pertanian Bogor. 